\title{
MIDAS
}

Museus e estudos interdisciplinares

$8 \mid 2017$

Dossier temático "Objetos e museus: biografias, narrativas e vínculos identitários"

\section{El objeto patrimonial como símbolo identitario en el museo}

The heritage object as an identity symbol in the museum

\section{Carmen Gómez-Redondo}

\section{CpenEdition}

\section{Journals}

Edición electrónica

URL: http://journals.openedition.org/midas/1216

DOI: $10.4000 /$ midas. 1216

ISSN: 2182-9543

\section{Editor.}

Alice Semedo, Paulo Simões Rodrigues, Pedro Casaleiro, Raquel Henriques da Silva, Ana Carvalho

Referencia electrónica

Carmen Gómez-Redondo, «El objeto patrimonial como símbolo identitario en el museo », MIDAS [En

línea], 8 | 2017, Puesto en línea el 31 julio 2017, consultado el 19 abril 2019. URL : http://

journals.openedition.org/midas/1216; DOI : 10.4000/midas.1216

Este documento fue generado automáticamente el 19 abril 2019.

\section{cc) (†)}

Midas is licensed under a Creative Commons Attribution-NonCommercial-ShareAlike 3.0 International License 


\title{
El objeto patrimonial como símbolo identitario en el museo
}

The heritage object as an identity symbol in the museum

\author{
Carmen Gómez-Redondo
}

\section{NOTA DEL EDITOR}

Artigo recebido a 30.03.2017

Aprovado para publicação a 28.06.2017

\section{Introducción}

1 El concepto de acervo patrimonial ha ido evolucionando desde una composición de objetos y conceptos heredados hacia una visión más holística y ecosófica (Guattari 1996), donde el ser humano es una parte más del sistema que coadyuva en la gestión del todo. Parte de esos procesos de interacción con el sistema ecológico son los procesos de patrimonialización, que responden al carácter integrador de las tres ecologías (subjetiva, social y medioambiental) (Guattari 1996), pero además tienen como fin último la continuidad temporal del sistema. El patrimonio, detenido en un lapso temporal, pretende la contextualización del acervo en el ahora (esto supone la integración de objetos y conceptos contemporáneos) para elaborar y proyectar el sistema al espacio temporal futuro. Este sistema/acervo pasado y futuro lleva adscrita inherentemente una selección; en primer lugar, debido a la imposibilidad de legar absolutamente todos los productos elaborados por una generación (ecología medioambiental), y seguidamente por la dificultad añadida de la diversidad de criterios (ecología social y subjetiva) que varían según qué disciplinas, según qué valores, qué agentes y según qué épocas (Fontal 2003). Sin embargo en toda selección intencionada queda implícito un carácter positivista, una finalidad legataria del bien común, de la identidad colectiva y de pertenencia econsciente al sistema, que hará que de aquí en adelante al conjunto de elementos tangibles e 
intangibles que conforman el patrimonio lo denominemos bajo el término bienes culturales, quedando recogidas en él tanto la diversidad como la finalidad de la transmisión.

El patrimonio se presenta como resultado de un proceso contemporáneo realizado a partir de un sistema heredado, objetos y procesos que en cada reelaboración presente son seleccionados:

Las cosas que tienen un sentido para nosotros, no pueden abandonarse, como si flotasen en la mera trascendencia, y por eso describimos, analizamos, comparamos, juzgamos y clasificamos; por eso, construimos teorías acerca de la creatividad, la forma, la percepción, la función social; también por eso consideramos que el arte es un lenguaje, una estructura, un sistema, un acto, un símbolo, un modelo de sensaciones. (Geertz 1994, 118)

Para unirse al hilo de los bienes que conforman este proceso contemporáneo de transmisión histórica o errancia (Falcón y Torregrosa [2014]), «no es el pasado el que produce el presente, sino a la inversa, el presente quien configura el pasado. La tradición, de tal modo, más que madre es hija del presente» (Marcos 2010, 3).

Desde este punto de vista el patrimonio puede concebirse como un acervo, una colección de bienes en continua mutación de generación en generación que ante nosotros se presenta desde este enfoque, como un sistema, como letras/objeto de una historia cuya narración «da cuenta de la personalidad de la comunidad con la que se identifica, es decir, de su cultura» (Aguirre 2008, 88). Pero además, este acervo se presenta también como argumento (fig. 1) y en cuanto a tal, contribuye a la continuidad histórica (Ballart 1997).

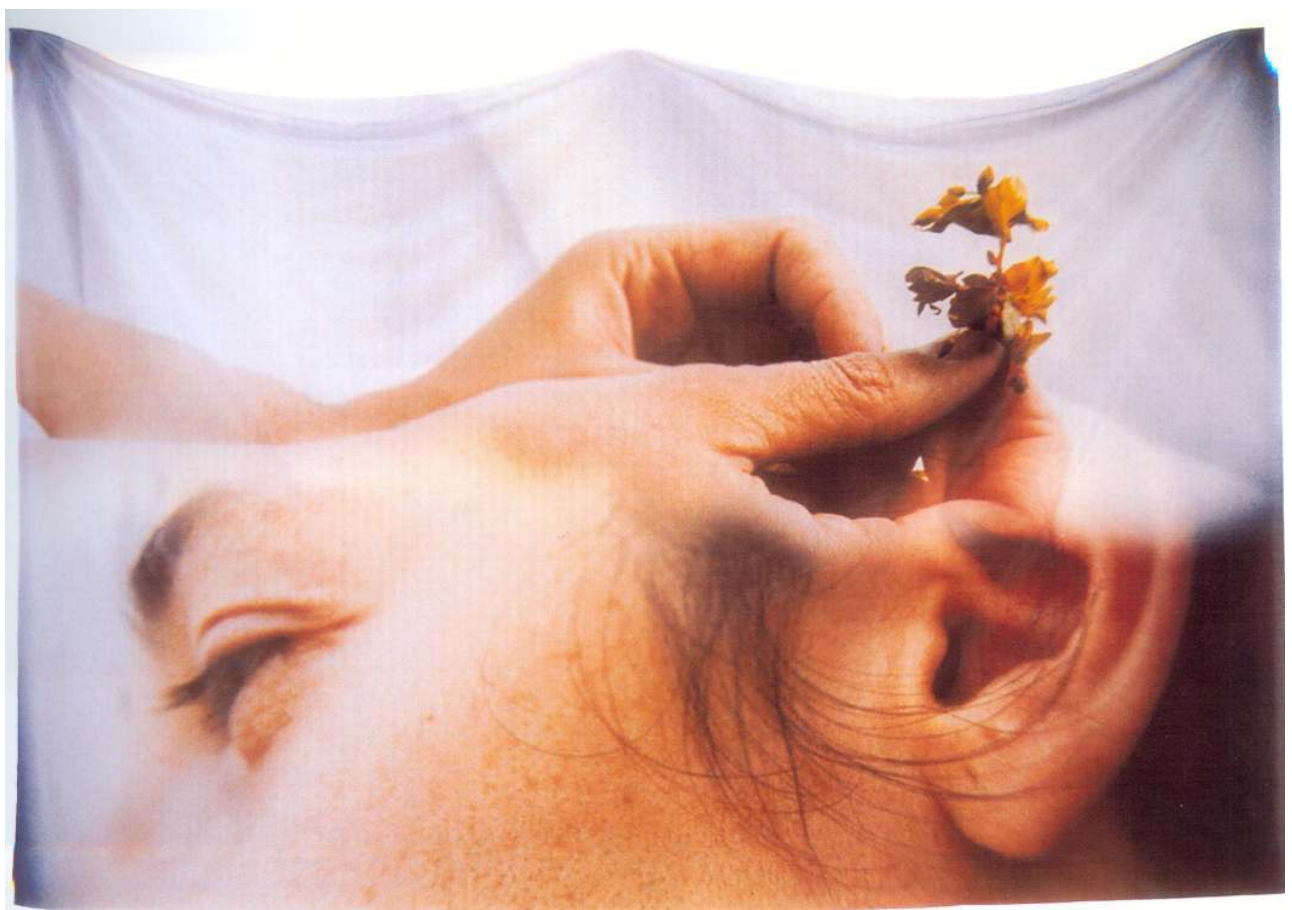

Fig. 1 - Me despertaré engañada, 2002

Fotografía de María José Gómez Redondo

De la afirmación de Aguirre cabe extraer que cada objeto no revierte tan sólo en su mismo significado, sino que posee una capacidad evocadora, incluso una capacidad semiótica para simbolizar aquello a lo que no significa directamente desde lo icónico. El patrimonio se desvincula de su funcionalidad, los bienes culturales pasan de ser utilizados a ser 
poseídos (Baudrillard 2010), desposeyéndose también de su significación, para finalmente simbolizar:

Parecen contradecir las exigencias del cálculo funcional para responder a un deseo de otra índole: testimonio, recuerdo, nostalgia, evasión. Se siente la tentación de descubrir en ellos una supervivencia del orden tradicional y simbólico. Pero estos objetos, por diferentes que sean, forman parte también de la modernidad y cobran en ella su doble sentido. (Baudrillard 2010, 83)

De manera inversa a la aculturación de lo heredado propuesta por el autor (Baudrillard 2010), la simbolización responde a una enculturación del bien, la atribución de significados del pasado, del presente y del futuro desde este proceso de remodelado concebido por la cultura contemporánea.

7 Esta reflexión da pie al discurso desarrollado a lo largo del artículo cuyo objetivo principal es poner en valor el papel agente del museo en la creación de identidades y en los procesos de identización. Para ello se sigue una línea de reflexión teórica a través de un estado de la cuestión. Este estado de la cuestión se sustenta en tres líneas de investigación: educación en museos, semiótica del objeto y la educación patrimonial y dentro de ésta, nos centraremos en los procesos de identización.

\section{El objeto y lo humano}

Durante 1975, Pier Paolo Pasolini escribe una serie de artículos en forma de cartas dirigidas a un joven napolitano figurado, de nombre Gennariello. A lo largo de las entregas que conforman este 'pequeño tratado pedagógico', Pasolini reflexiona acerca de aspectos relacionados con la educación y los aprendizajes adquiridos a lo largo de la vida, y describe las distintas 'fuentes educativas' que conforman la identidad de la persona. En su clasificación señala la 'enseñanza de las cosas', el aprendizaje que se desprende del mundo sensible, como la más significativa de todas.

De acuerdo con ella, nuestra experiencia sensible queda configurada desde el nacimiento por los objetos que nos rodean, al tiempo que nos posiciona y define el modo en que nos relacionamos con el mundo. Además, la impronta que deja ese aprendizaje es muy difícil de borrar o transformar a lo largo de la vida, ya que queda grabado en el niño desde su más tierna infancia: 'La educación que a un muchacho le dan los objetos, las cosas, la realidad física - en otras palabras, los fenómenos materiales de su condición social - convierte a ese muchacho al mismo tiempo en lo que es y en lo que será durante toda su vida. Es su carne la que es educada como forma de su espíritu'. (Martínez 2011, 69)

8 Con este texto de Martínez sobre Las Cartas Luteranas de Pasolini (1997) pretendemos hacer una llamada de atención sobre la importancia de los objetos para la interpretación del mundo en el que vivimos y para la interpretación de nosotros mismos a nivel subjetivo y social (Falcón y Torregrosa 2014).

9 Si bien es cierto que los objetos no se significan por sí mismos, y en cuanto a esto, es necesaria una enculturación desde las personas para el uso y sentido de éstos. Muchos de esos significados y sentidos son fruto de una significación individual, es decir, el individuo aprende a aprender con los objetos (Semedo 2015).

10 Clasificados ya desde cierta perspectiva, los objetos adquieren la categoría de productos culturales, en tanto en cuanto son significados desde un ámbito cultural concreto y ayudan al individuo a dotar de sentido a ésta. Son por tanto productos simbólicos: 
El patrimonio es este asterismo contragráfico, simultáneamente inconsciente e instintivo que nos introduce en una dimensión relacional e imaginal con infinita carga simbólica y metafórica. Situación que se revela en cada encuentro íntimo con lo patrimonializable, haciendo de la experiencia un nacer colectivo al margen de todo lo que entumece. (Falcón 2015, 285)

11 Esta significación y dotación de sentido hace referencia no sólo a los productos generados por los hombres, sino a los objetos y fenómenos que aparecen en el entorno natural pero que, al dotarlos de significado y sentido, se tornan productos culturales de ésta, reforzando la idea del sistema holístico sostenido desde la ecosofía (Guattari 1996).

\section{Los objetos clasificados}

12 Los objetos como materialidades polisémicas del universo simbólico de cada cultura, actúan como agentes enculturadores, y permiten en su materialidad dar prueba y experiencia de los límites taxonómicos de cada cultura. Sirva como ejemplo de este poder de experiencia inter-taxonómica el urinario obra de Marcel Duchamp, marcado como hito en las vanguardias artísticas. Este urinario en tanto que objeto cultural destinado al depósito y traslado de los fluidos corporales humanos y masculinos, es permutado taxonómica y categorialmente al significado de producto artístico. Este aspecto transcultural, como objeto que aún atiende a ambas categorías, es lo que le dota de un carácter transgresor y da cuenta de los procesos culturales: enculturizadores $\mathrm{y}$ enculturizados, que se transmiten asociados a un objeto. «[...] todo objeto transforma alguna cosa, el grado de exclusividad o de socialización en el uso (privado, familiar, público, indiferente), etcétera» (Baudrillard 2010, 2).

Podemos por tanto hablar de un sistema de los objetos, en cuanto a su clasificación y función en la cultura que lo produce, los objetos cambian de significados y usos en tanto en cuanto se inscriben en un sistema cultural dinámico y mutable.

Y, para decirlo todo de una vez, la descripción del sistema de los objetos tiene que ir acompañada de una crítica de la ideología práctica del sistema. En el nivel tecnológico no hay contradicción: solo hay sentido.

Pero una ciencia humana tiene que ser del sentido y del contrasentido: de cómo el sistema tecnológico coherente se difunde en un sistema práctico incoherente, de cómo la 'lengua' de los objetos es 'hablada', de qué manera este sistema de la 'palabra' (o intermediario entre la lengua y la palabra) oblitera al de la lengua. (Baudrillard 2010, 8)

El autor propone aquí esa doble naturaleza simbólica, a través del instrumento como tecnología, como objeto funcional, y la palabra, como significado y sentido de los objetos, y por tanto a su potencialidad polisémica. Baudrillard propone una clasificación, un sistema de los objetos que dibuja el sentido y contrasentido del objeto, vuelve por tanto, a la idea del objeto enculturizador, al que posee significado y puede, al ser parte de un sistema, dejar de tener dicho significado, poniendo de manifiesto las estructuras culturales del individuo que lo interpreta. Esta doble naturaleza supone poder hablar de un sistema funcional en el que el objeto no está definido en cuanto a una finalidad o función, sino que está definido en cuanto a un sistema y su integración en éste. Esta funcionalidad es la que le permite al objeto "viajar" por los diversos significados y categorías culturales. Este mundo funcional se caracteriza por:

La coherencia del sistema funcional de los objetos proviene de que éstos (y sus diversos aspectos, colores, formas, etcétera) no tienen valor propio, sino una 
función universal de signos. El orden de la Naturaleza (función primaria, pulsión, relación simbólica) se halla por doquier presente, pero sólo como signo. La materialidad de los objetos ya no choca directamente con la materialidad de las necesidades. Hay elisión de estos dos temas incoherentes, primarios y antagónicos en virtud de la inserción entre uno y otro de un sistema abstracto de signos manipulables: la funcionalidad. Al mismo tiempo, la relación simbólica desaparece: lo que se trasluce a través del signo es una naturaleza continuamente dominada, elaborada, abstracta, es una naturaleza sistematizada: una naturalidad (o ' culturalidad' si se prefiere). Esta naturalidad, por consiguiente, es el corolario de toda funcionalidad. Es la connotación moderna del sistema de 'ambiente'.

La presencia perpetuamente rebasada de la Naturaleza (de modo mucho más coherente y exhaustivo que en todas las culturas anteriores) confiere a este sistema su valor de modelo cultural y su dinamismo objetivo.

Pero la presencia constantemente desmentida de la Naturaleza es también de hecho un sistema de desconocimiento, de falta, de coartada (por lo demás, más coherente también que todos los que lo precedieron). (Baudrillard 2010, 66-67)

Se dibuja respecto de esta tradicionalidad un sistema funcional, basado en la relación del objeto con su ambiente y con otros objetos, así como con su uso; en contrapartida aparece el sistema disfuncional (Baudrillard 2010), los objetos abstraídos de toda contextualización que generan su propio contexto trans-histórico y trans-categórico (fig. 2). Sería éste el caso de los objetos de colección y los objetos antiguos. Además el autor propone un sistema metafuncional y disfuncional (Baudrillard 2010), en el que trasciende la funcionalidad y comienzan a generarse aberraciones, seudofuncionalidades $o$ metafuncionalidades.

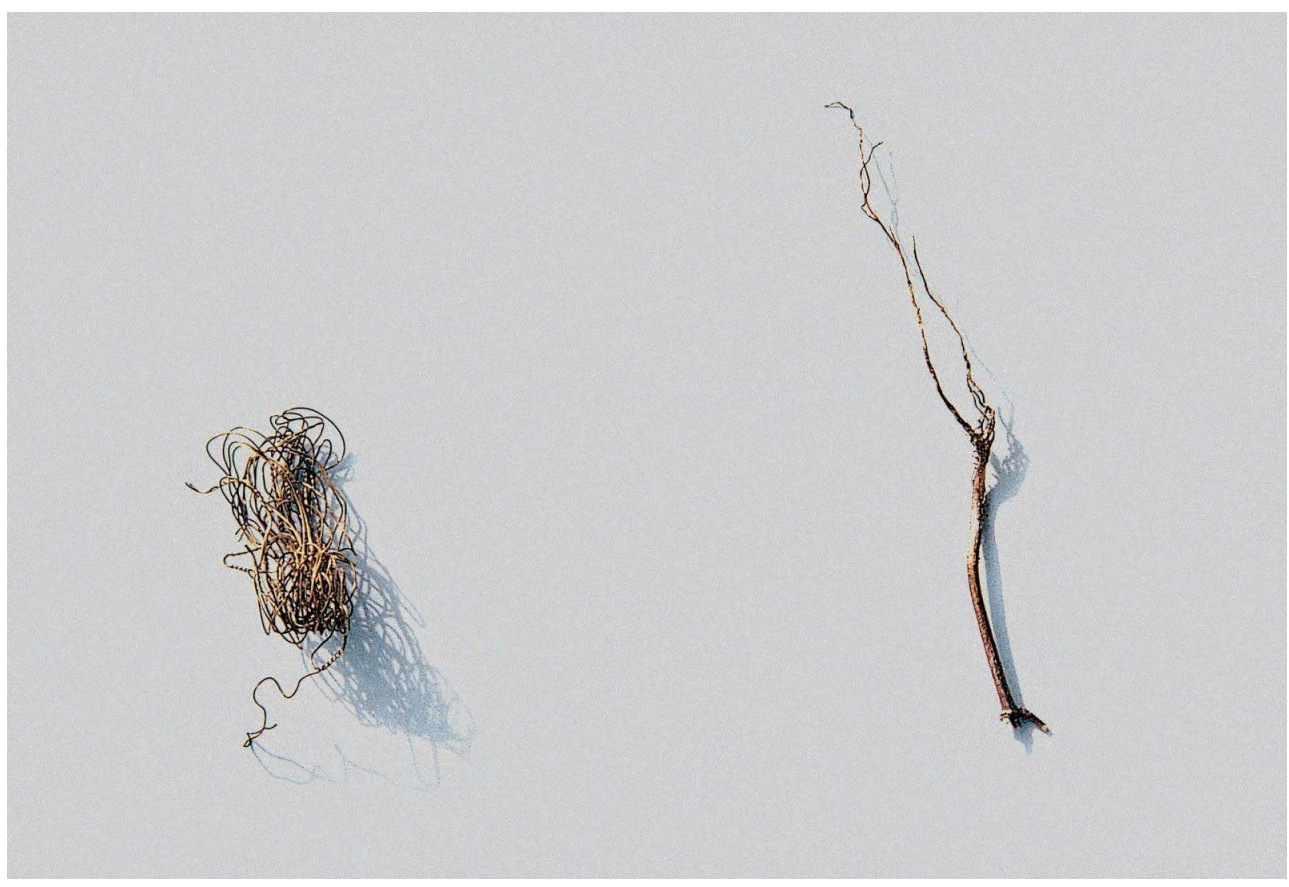

Fig. 2 - Somos lugares de hilo, 2014

Fotografía de María José Gómez Redondo

En lo relativo a lo patrimonial, tal vez sea interesante adoptar el sistema artístico propuesto por Falcón (2015), que pretende procesos erráticos, creativos y que den lugar al encuentro con otros:

El desarrollo de un sincero pensamiento patrimonial implica inmersión en la experiencia artística, en un proceso errático, onírico y comprensivo que ofrece un 
conocimiento insólito. Realidad que nos seduce y abre pasajes hacia otros laberintos de los real, de lo patrimonial. La experiencia artística ligada al patrimonio hace posibles viajes abiertamente creativos, vivencia que invitan a sumergirse en todos los pliegues oscuros o desconocidos de la existencia, donde las potencias arquetípicas respiran. (Falcón 2015, 287)

Es por tanto, un sistema de recreación e interacción ya que:

En este sentido, el arte tampoco existe en sí mismo de manera independiente, sino que somos nosotros quienes lo alumbramos en un continuo proceso interior $y$, también, de interacción. Creo que ese vivir consciente de cada instante de alumbramiento podría ser uno de los pilares para abordar la enseñanza del arte contemporáneo desde una dimensión más humana, más cercana a la vida cotidiana. (Zaera 2015, 250)

Entendemos pues, a la luz de estas explicaciones, que el objeto se interpreta y recrea contextualizado en su sistema, carece de significados propios y los que se puedan dar de forma espontánea, creativa y errática, refieren a potencias arquetípicas (Falcón 2015), a lo subjetivo y a lo colectivo. Finalmente, desprovistos de todos ellos se convierte en objetos disfuncionales.

\section{La relación entre los objetos}

19 En base a los significados y polisemias que el objeto puede poseer, se establecen categorías y taxonomías que los relacionan con otros objetos. De este modo, se pueden clasificar herramientas, objetos estéticos, cuyo material es el plástico o la madera, uniéndolos en un objeto mayor como puede ser un motor, y un largo etcétera, una serie de discursos interobjetuales, establecidos culturalmente. Estos discursos establecidos por el hombre pueden hacer referencia a sus cualidades naturales, desprovistas en muchos casos de una humanización radical ${ }^{1}$, o bien hacer referencia a un discurso simbólico producto de la cultura o del individuo.

Aquí, se hace evidente que estas poéticas de seleccionar y organizar objetos son un medio para unir las narrativas de vida a través de las cosas, a menudo efímeras, y son a la vez un acto íntimo y un fenómeno de grupo. (Semedo 2015, 133)

Los objetos, por tanto, se relacionan y forman una narración propia y cultural, hasta el punto de poder generar narraciones en el presente desde el pasado. Ejemplo de ello son las exposiciones arqueológicas, o incluso dar luz y materialidad a procesos culturales más complejos como puede ser una exposición artística (fig. 3). 


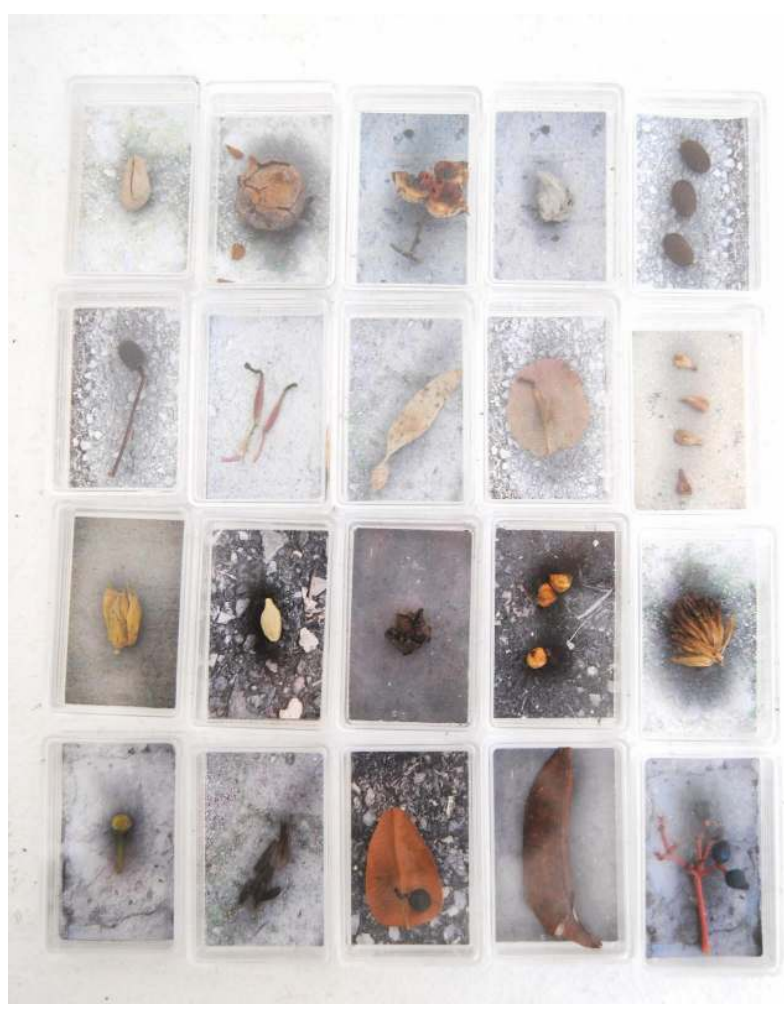

Fig. 3 - Semillas, 2014

Fotografía de María José Gómez Redondo

21 Sin embargo, estas narraciones tienen plena expresión en el contexto que lo determina, tanto el objeto como las relaciones que establece con otros objetos vienen definidas por ese contexto. De esta forma, y siguiendo el ejemplo propuesto anteriormente, el urinario de Duchamp es considerado arte, por el público porque interpreta el objeto en un contexto artístico ya que si ese mismo urinario estuviese anclado en la pared de un aseo no sería significado del mismo modo. El objeto aquí es significado en base al contexto de referencia, aunque también puede serlo en base a los objetos con los que se relaciona. No se significa de la misma manera el urinario rodeado de obras de arte de mediados del siglo $\mathrm{XX}$, que de grifos y sanitarios; $\mathrm{y}$, del mismo modo, el contexto condicionará o será condicionado por la narración de los objetos. De esta manera, si se presenta el urinario de Duchamp en una calle, el contexto significará al objeto y será interpretado como basura, mientras que si el urinario se rodea de otras obras de arte, la narración de los objetos supera a su contexto, y lo significa. Podría decirse entonces, que el arte ha salido a la calle recontextualizando el entorno.

Efectivamente, la noción de contexto se puede ir haciendo cada vez más compleja a medida que los elementos que constituyen los contextos se hacen más complejos y podemos entonces hablar del contexto de los contextos o de un determinado grupo de contextos. Para no caer en un juego de palabras, sintetizaremos la cuestión subrayando que entre el todo y las partes, entre el contexto y sus componentes se da una relación dialéctica, de manera que se necesitan mutuamente por construir una misma realidad. (García Blanco 1994, 11)

Finalmente y recapitulando, podríamos decir que el objeto se configura como construcción vacía, sobre la que anexionar significados que ayudan al individuo, en su proceso de enculturación, a dotar de sentido al entorno. Estos significados pueden posicionar al objeto como funcional, en cuanto a que tiene un sentido en la cultura, o bien 
significarlo de forma disfuncional, es decir, una perversión de estos significados. Ambos, sentido y contrasentido, ponen en marcha un proceso efectivo de enculturación, donde el individuo aprende y aprende a aprender a través de los objetos.

\section{El objeto en el espacio}

Desde los significados atribuidos a los objetos ha sido posible establecer una narración e incluso un contexto para ella; como enunciábamos, contexto y objeto se construyen en base a relaciones dialécticas, se resignifican en el dinamismo cultural. De este modo, podemos hablar de un sistema más complejo, de objetos que significan a contextos y cobran cuerpo en un espacio y entidad concreta, el museo:

Estas heterotopías en fin muestran que el espacio es una tan fuerte metonimia de las instituciones y de la vida en ellas que se convierte en su hipóstasis. Las instituciones y totales hacen mundos totales, como si el mundo llegara hasta y acabara en sus muros exteriores, como si tuvieran capacidad sobrada de contener el tiempo de las vidas de los internos. La totalidad es una gran ficción cuya fortaleza es el espacio que ocupan y dominan y las formas que adopta. Así éstas heterotopías no son sólo otros lugares, son los lugares de los otros. (Velasco 2007, 435)

Personas, objetos y ahora espacios, tienen un papel activo en el proceso enculturizador del individuo. El espacio y los significados de los que se le dotan aportan al individuo nuevos contextos y por tanto materialidades categóricas.

Una posible propuesta de museo que va más allá de sus paredes y que busca en su contexto los significados es el ecomuseo. Sin embargo, al menos en los modelos a los que referían autores como Tielve (2004) y Varine-Bohan (2007), el museo aludía a la contextualización de la comunidad en su proceso histórico, y a partir de ahí comenzaba el discurso del ecomuseo. Desde nuestro punto de vista entendemos que la postmodernidad ha generado nuevos procesos culturales y nuevos significados que no pueden encontrar contexto en la historia, ya que anteriormente no se habían producido.

Proponemos, en este caso, el museo enculturador, que comparte con el ecomuseo ese punto de vista antropológico y es consciente de su papel, ya no para la sociedad, sino que se significa en la sociedad. Aludimos aquí a un museo que ayuda a significar desde su colección o su ideario a la comunidad. Un museo que establece relaciones y construye contextos para generar relaciones, este entorno holístico que pretende educar o enculturizar a través de su propia identidad (Gómez-Redondo y Fontal 2017).

De este modo podríamos definir una serie de características que definen el museo enculturador:

- consciente de su papel activo en la sociedad comprende su colección como herramienta y no como fin;

- se establece como contexto, como locus cognitivo, desde el que establecer tipos de relaciones con la comunidad y a través de la comunidad;

- es consciente de su contexto, pero no se agota en él, al igual que los diferentes colectivos se inscriben en identidades más amplias, el museo enculturador se significa en lo común humano;

- establece un diálogo; no solo participa de la sociedad sino que permite sugerencias y propuestas en su dintorno;

- entre sus estrategias de educación y acción busca modelos globales que posibiliten las relaciones entre disciplinas y ámbitos; 
- atiende a diversos ámbitos educativos y de acción social y cultural;

- promueve la construcción de significados simbólicos en términos de propiedad e identidad;

- cataliza la construcción de patrimonios, no como acervo, sino como enfoque, lo que supone generar vínculos significativos con objetos o conceptos del entorno;

- contribuye a la construcción de la identidad individual y colectiva a través de su labor catalizadora de patrimonios. (Gómez-Redondo 2013, 48)

De este modo, el museo enculturador, en su cualidad de agente social y cultural tiene como misión dar a conocer la cultura generada en su contexto, pretende la integración de individuos y comunidad para la plena concienciación en su presente. Extiende su acción en el presente, para contextualizar y generar comunidad e identidad, de este modo se identifica a sí mismo.

When we switch our perspective to identity as process, we become less concerned about what a visitor's identity is, and more concerned about what the visitor is doing about the problem of identity. By switching the analytical perspective from "identity" to "identity work," we eliminate the need to measure, name, and categorize the identities visitors are presumed to bring into the museum. We then can turn our attention to how the visitor uses the museum in his or her lifelong work of identity construction, maintenance, and change. (Rounds 2006, 135)

Como subyace a las palabras del autor, el cambio de perspectiva en el concepto de identidad (Gómez-Redondo 2012) permite cambiar los enfoques del museo, de la investigación y la acción educativa. Así pues, la atención no se centra tanto en clasificar al público; el museo deja de ser una entidad desde la que se conceptualiza e investiga a los visitantes en términos de cantidades y estadísticas, para comprender al público desde una perspectiva cualitativa y procesual, es decir, cambiante. Es en esta cualidad dinámica en la que el museo toma una agencia ante este dinamismo, es decir, se formula como agente de cambio, que a través de la acción formativa, cataliza y se inscribe en la formación de la identidad del visitante. El museo se ha posicionado en las últimas décadas en un lugar agente dentro del sistema cultural; ha evolucionado desde un carácter meramente acumulativo y custodio, propio de concepciones más clásicas, hacia un protagonismo social, es decir, el museo se ha dejado de centrar en su interior para volver la mirada hacia el exterior y el público. Este cambio de perspectivas ha quedado reflejado en la creciente relevancia que han tomado los departamentos de educación, comunicación y difusión dentro del museo.

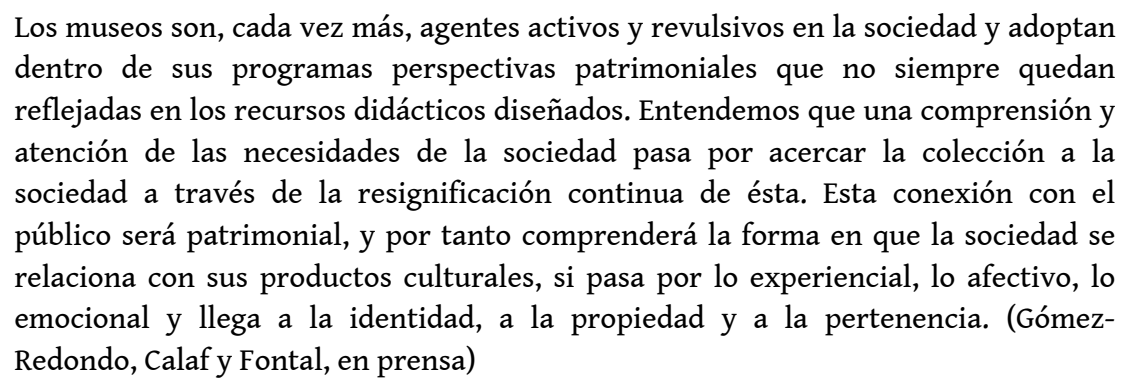

Así pues, el museo se configura hoy como contexto real, no como mero escenario o entorno que no condiciona lo que sucede en su interior, sino que, como contexto influye y determina los nuevos procesos identitarios que concurren entre sus muros: el museo ofrece oportunidades tanto para confirmar nuestra identidad actual como para explorar, de manera segura, otras identidades. 
31 Existen, en cuanto a universo de oportunidades, multitud de fenómenos, procesos, herramientas, de las que el entorno museístico es responsable, tantos como individuos, actitudes, experiencias previas e identidades encuentren cabida en este entorno; sin embargo, y teniendo como referencia la propuesta de Rounds (2006), destacaremos aquí tres características concretas del museo: el museo como lugar de intensificación del sentido, su carácter performativo y su cualidad de presentación de lo exótico, a nuestro entender de lo patrimonial.

Para Rounds (2006) el museo se comprende como dador de sentido dentro de un orden ontológico, en su cualidad de seleccionador de los elementos del entorno, así pues, para el autor entrar en el museo supone comprender un cierto sentido del entorno, que responde a una estructura de orden que sirve de ejemplo para la construcción identitaria:

Museums are in that line of business. They take the stuff of the world, and they present it arranged by some principle of order. They provide vantage points from which the order that's invisible in quotidian life becomes intensified and visible in the space of an exhibition. (Rounds 2006, 140)

En este sentido el museo supone una intensificación del entorno, como nodo explícito del sistema cultural y como tal, contribuye a la construcción ordenada del sentido dentro de la identidad del individuo, es decir, el museo cataliza los procesos de ordenación de configuración de la 'mochila' experiencial del individuo en tanto en cuanto ordenan y ofrecen puntos de vista del entorno.

The results of a study of visitors to the Museum of Scotland, in Edinburgh, [42] McLean and Cooke, 'Communicating Identity'. Demonstrated that visitors give complex, often contradictory, meanings to museum objects, meanings that are representative of their personal perceptions of identity. The museum was a place where people actively made and remade their identities. They selected, rejected and manipulated the identities found, in a way that was guided by their needs at that particular time. (Newman y McLean 2016, 64)

Aparecen pues como contextos en los que formar comunidades de interpretación, es decir, comunidades de pertenencia o finalmente, identidades colectivas.

En este carácter colectivo, y entendiendo la identidad desde su sentido cultural, Rounds (2006) hace referencia al carácter performativo del museo. El museo se presenta aquí como la otredad dialógica de la identidad individual, es decir, partiendo de la noción inicial de que la identidad se compone en parte, como respuesta al entorno y en base a éste, la otredad se presenta como performativa, en tanto en cuanto supone un ámbito de praxis de la idea abstracta de identidad. Visitar el museo supone poner en práctica, activar, la identidad y activar procesos de identización, y por tanto supone dotar al museo de una cualidad performativa, en cuanto agente de cambio, es decir desde la otredad.

Entendemos el carácter performativo al que alude el autor, en base a los significados patrimoniales atribuidos al arte, es decir, algo se convierte en performativo cuando los significados culturales que contiene, lo convierten en potencial materia identitaria. No es posible que algo se impregne hasta lo más profundo de la identidad si no ha sido significado de tal manera que lo permita profundizar; por tanto, esta significación otorga una capacidad de penetración, donde dicha capacidad podría comprenderse dentro del ámbito de lo patrimonial, es decir, es la significación en lo patrimonial lo que permite acceder a la identidad.

37 Así desde lo performativo es posible llegar a la tercera cualidad del museo que expone el autor como potencial agente identitario, ésta es la exposición de lo exótico. Definiendo lo 
exótico como extraño o peculiar, es posible establecer un paralelismo con lo patrimonial, en tanto en cuanto la relevancia de significación y valoración, ambos conceptos, exótico y patrimonial atribuyen un valor a ciertos objetos o manifestaciones por encima de sus iguales, esa cualidad pregnante o relevante es lo que les hace únicos y susceptibles de ser expuestos en un museo. Sin embargo, el significado patrimonial, a diferencia de lo exótico, se posiciona, en su significación, entre lo peculiar y lo identitario, es decir, supone un potencial cambio en la identidad, frente a lo exótico que se configura como significado y cualidad propia sin apertura dialógica.

Sin embargo, y como bien señala Rounds, los cambios identitarios en el museo no son cambios significativos, resulta extraño un cambio identitario radical. Entendemos que el cambio identitario en el museo es un cambio que afecta a la agencia y a la capacidad creativa respecto de la propia identidad, es decir, posibilita la toma de consciencia del carácter constructivo de la identidad y posibilita y dota de herramientas para el cambio, sea éste cuando se precise.

I agree that dramatic transformations of identity during museum visits will be extremely rare. They don't happen anywhere very often, so it would be surprising if they did in museums. As Doering and Pekarik have argued, most visitors seek to have their "entrance narratives" confirmed, not challenged (1996).

However, I don't think that sudden, dramatic transformations are what we should be looking for. From the process perspective of the identity work model, the visitor may be seen instead to be using the museum experience as a way of building capacity for transformations that may or may not happen at some time in the future.

I have chosen to label this "identity exploration," to emphasize the point that it involves searching for things as yet unknown. As argued earlier, identity is the site of constant negotiation between structure and agency. When we use museum experiences to do identity maintenance, we seek out structures (both cognitive contents and behavioral roles) that are consistent with our current narrative of identity, and so confirm and strengthen that identity. By contrast, when we use the museum for identity exploration, we cultivate the independence of our sense of personal agency by adopting roles and exploring contents that are inconsistent with the structures that define our current identity. (Rounds 2006,143)

El museo se configura como contexto activador, de lo que se propone como acciones y herramientas para posibilitar el proceso de identización. Es en este entorno específico donde es posible, a través del arte, construir las propias herramientas para el cambio, y por tanto es en este entorno además, desde donde se impulsa la creación de nuevas identidades colectivas a través de la acción educativa.

\section{Conclusión}

40 A lo largo de estas líneas hemos intentado introducir al lector en lo complejo del término objeto, así pues cuando hablamos de un objeto no hablamos de una 'cosa' sino más bien de un sistema simbólico que representa a la cultura en la que se inscribe y a los procesos metaculturales de ésta. Dentro de este sistema de simbolización podríamos introducir el término patrimonio, no como un acervo de elementos sino como parte de esos procesos metaculturales y en cuanto a esto, el patrimonio es definido como un vínculo significativo que los individuos otorgan a las diferentes manifestaciones culturales y, en este caso a los objetos. Esta re-conceptualización genera nuevas formulaciones en torno a la conservación y generación del patrimonio que visto desde la relación objeto/sujeto hace 
necesaria una intervención desde el ámbito educativo, concretamente desde la educación patrimonial, entendida aquí como instrumento para este fin y concebida para un pleno desarrollo del individuo en la sociedad.

41 Tras esta enmarcación de los procesos metaculturales, tiene lugar la concreción de la acción educativa en el ámbito museístico centrándose en el papel agente del museo en la conceptualización de la educación en la vida. Por tanto, el nuevo paradigma de museo de arte contemporáneo resulta un museo enculturador que no solo se acerque a la interpretación plástica de las obras de arte, sino que se acerque desde la diversidad de perspectivas que demanda la sociedad, entre ellas la identitaria.

\section{BIBLIOGRAFÍA}

Aguirre, Imanol. 2008. "Nuevas Ideas de Arte y Cultura para Nuevas Perspectivas en la Difusión del Patrimonio." In El Acceso al Patrimonio Cultural. Retos y Debates, 67-118. Pamplona: Universidad Pública de Navarra.

Ballart, Josep. 1997. El Patrimonio Histórico y Arqueológico: Valor y Uso. Barcelona: Ariel.

Baudrillard, Jean. 2010. El Sistema de los Objetos. Madrid: Siglo XXI.

Falcón, Roberto Marcelo, y Apolline Torregrosa Laborie. [2014]. Ser el Sitio. Disponible en: https:// www.academia.edu/12978771/Ser_el_sitio. (consultado en Junio 29, 2017).

Falcón, Roberto Marcelo. 2015. "Patrimonio Errático.” In Educación y Patrimonio. Visiones Caleidoscópicas, coords. Olaia Fontal, Silvia García-Ceballos, y Alex Ibáñez 279-290. Gijón: Trea.

Fontal, Olaia. 2003. La Educación Patrimonial: Teoría y Práctica para el Aula, el Museo e Internet. Gijón: Trea.

García Blanco, Ángela. 1994. Didáctica del Museo: El Descubrimiento de los Objetos. Madrid: Ediciones de la Torre.

Geertz, Clifford. 1994. Conocimiento Local. Ensayos sobre la Interpretación de las Culturas. Barcelona: Paidós.

Gómez-Redondo, Carmen, Roser Calaf, y Olaia Fontal. (en prensa). Diseño de un Instrumento de Análisis en Recursos Didácticos Patrimoniales. Cadmo: Revista de História Antiga.

Gómez-Redondo, Carmen, y Olaia Fontal. 2017. "Procesos de Identización en el Arte Contemporáneo: Construir una Identidad Colectiva a través de una Cartografía Identitaria en la Red. Cuadernos de Música, Artes Visuales y Artes Escénicas 12 (2): xx-Xx.

Gómez-Redondo, Carmen. 2012. “Identización: La Construcción Discursiva del Individuo.” Arte, Individuo y Sociedad 24 (1): 21-37.

Gómez-Redondo, Carmen. 2013. "Construir la Identidad en el Entorno Museístico. Discursividad entre el Individuo y el Arte." RdM, Revista de Museología: Publicación Científica al Servicio de la Comunidad Museológica 57: 44-53.

Guattari, Félix. 1996. Las Tres Ecologías. Valencia: Pre-textos. 
Marcos, Javier. 2010. "El Patrimonio como Representación Colectiva. La Intangibilidad de los Bienes Culturales.” Gazeta de Antropología 26 (1). http://hdl.handle.net/10481/6799

Martínez, Pablo. 2011. “La Educación como Práctica Estética... y Algunas Notas sobre el Trabajo en el CA2M." In Perspectivas Situación Actual de la Educación en los Museos de Artes Visuales, coord. María Acaso, 69-72. Madrid: Ariel y Fundación Telefónica.

Newman, Andrew, y Fiona McLean. 2006. “The Impact of Museums upon Identity.” International Journal of Heritage Studies 12 (1): 49-68.

Rounds, Jay. 2006. “Doing Identity Works in Museums." Curator: The Museum Journal 49 (2): 133-150.

Semedo, Alice. 2015. "Los Objetos Performativos como Herramientas de Aprendizaje en la Formación de los Profesionales de los Museos." In Educación y Patrimonio. Visiones Caleidoscópicas, coords. Olaia Fontal, Silvia García-Ceballos, y Alex Ibáñez, 121-136. Gijón: Trea.

Tielve, Natalia. 2004. “Un Modelo Participativo en la Gestión del Patrimonio: El Ecomuseo.” In Comunicación Educativa del Patrimonio: Referentes, Modelos y Ejemplos, coords. Roser Calaf, y Olaia Fontal, 137-155. Gijón: Trea.

Varine-Bohan, Hugues de. 2007. “El Ecomuseo. Una Palabra, dos Conceptos, Mil Prácticas. Mus-A: Revista de los Museos de Andalucía (8): 19-29.

Velasco, Honorio. 2007. Cuerpo y Espacio. Símbolos y Metáforas, Representación y Expresividad de las Culturas. Madrid: Editorial Centro de Estudios Ramón Areces.

Zaera, Rossana. 2015. “Cajas de Memoria.” In Educación y Patrimonio. Visiones Caleidoscópicas, coords. Olaia Fontal, Silvia García-Ceballos, y Alex Ibáñez, 221-230. Gijón: Trea.

\section{NOTAS}

1. Empleamos este término, humanización radical, para referir a significaciones de objetos naturales de forma puramente cultural, es decir, se desvisten de significaciones naturales para ser puramente culturales. Este podría ser el caso de una silla de madera pintada. En oposición un caso de baja humanización radical sería una clasificación de los objetos naturales, es decir dotarles de sentido, como puede ser denominar a ciertos objetos árboles. Queda evidenciado que no puede existir un grado de humanización nulo, todo lo que existe ha sido percibido por el hombre, y en cuanto a esto, está humanizado.

\section{RESÚMENES}

La forma en la que los individuos se relacionan con los objetos determina la cultura y su transmisión. Lo metacultural de este proceso puede ser denominado patrimonio en el momento en el que entronca con lo identitario del individuo o la sociedad. A esta forma de interpretar el entorno la denominamos patrimonio y en ella no solo juega un factor fundamental individuo y objeto, sino también el entorno. Entendemos por tanto, el museo como contexto para producir cultura y por ello, como una variable a tener en cuenta en el desarrollo de la identidad. A lo largo 
de este artículo se pretende generar un discurso argumental que sustente este corolario a través de las propuestas de diversos autores referentes en la disciplina.

The way in which individuals relate to objects determines the culture and its transmission. The metacultural of this process can be called heritage at the moment in which it connects with the identity of the individual or society. This way of interpreting the environment we call it heritage and it not only plays a fundamental factor individual and object, but also the environment. We therefore understand the museum as a context for producing culture and therefore as a variable to take into account in the development of identity. Throughout this article it is intended to generate a discourse that supports this corollary through the proposals of various authors referring to the discipline.

\section{ÍNDICE}

Keywords: cultural heritage, identity, heritage education, identization, museum

Palabras claves: patrimonio cultural, identidad, educación patrimonial, identización, museo

\section{AUTOR}

\section{CARMEN GÓMEZ-REDONDO}

Licenciada en Bellas Artes en 2004 por la Universidad Complutense de Madrid y doctora en Educación en 2013 por la Universidad de Valladolid. Trabaja como profesora ayudante doctora en el Departamento de Didáctica de la Expresión Musical, Plástica y Corporal en la Universidad de Valladolid. En el ámbito de la investigación, pertenece al grupo de investigación de OEPE (Observatorio de Educación Patrimonial en España) y a la Red14 (Rede de Investigación en Enseñanza de las Ciencias Sociales), en los que investiga sobre educación patrimonial. Su principal línea de investigación son los procesos de identización y patrimonialización en el arte contemporáneo.

Facultad de Educación, Plaza de la Universidad, 1, 40005 Segovia, España, carmenez.gomez.redondo@gmail.com 